\title{
Alternativo
}

\section{O ENSINO SUPERIOR QUE DESEJAMOS}

Victor Emídio Campos (1)

\begin{abstract}
Resumo
O presente estudo tem como objetivo discutir o ensino superior que desejamos para os brasileiros e, a idoneidade dos professores em relação aos alunos no cumprimento de suas responsabilidades. Foi indagada a forma dos professores avaliarem e serem avaliados, e constatou-se que os principais atores necessitam de ações supervisionadas. Os resultados indicaram métodos de avaliação com necessidade de serem revistos, frente às novas realidades no processo de formação. Acreditamos que no instante em que o sistema valorizar mais o trabalho dos docentes, fornecendo-lhes salário digno, formação e orientação, os resultados positivos certamente aparecerão.
\end{abstract}

Palavras-chave: Avaliação educacional. Pedagogia. Ensino superior.

\section{Introdução}

O presente estudo pretendeu, à partir das orientações da Lei de Diretrizes e Bases da Educação do Brasil - LDB 9394/96, discutir a avaliação democrática no ensino superior, como forma de minimizar falhas e atitudes indesejadas na prática pedagógica.

Pensando numa perspectiva avaliativa mais eficiente e desejando um ensino superior de qualidade, é que se tem trabalhado e refletido sobre questões de avaliação nos cursos superiores. Inquieta-nos, também a seguinte questão: os professores da rede superior de ensino cumprem com competência e eticidade os indicativos proposto nas diretrizes educacionais?

Em termos metodológicos, optou-se pela abordagem bibliográfica e pelo trabalho de campo. A primeira teve como base uma revisão da literatura, com fichamento de livros e artigos, consulta a trabalhos monográficos e a livros de autores que lidam com a temática. No caso da pesquisa de campo, além dos contatos pessoais e visitas a instituições afins, foi elaborado questionário, direcionado a professores e alunos, os quais enfocam o processo da avaliação.

A princípio, o presente estudo diagnosticou as possíveis carências e necessidades dos educadores na aplicação e cumprimento nas exigências pedagógicas em relação às diretrizes 
educacionais brasileiras. Acreditamos que os resultados deste estudo possibilitarão o desenvolvimento do processo de ensino aprendizagem, principalmente, no tocante aos mecanismos de avaliação.

\section{As diretrizes e a avaliação na academia brasileira}

Tendo em vista o ensino superior que desejamos, faz-se necessário uma abordagem geral sobre as diretrizes curriculares nacionais, pois os PCNS constituem referenciais de excelente qualidade para a educação quando elaborado utilizando-se as técnicas necessárias, visto que se configura como proposta flexível a ser concretizada na medida em que as subdivisões curriculares nacionais, regionais, locais o autorize. O conjunto dessas proposições (Os PCNS) expressas à necessidade de referenciais, a partir dos quais, o sistema de ensino se articula e atua decisivamente no processo de construção da cidadania.

As estruturas das diretrizes e bases da educação nacional são por demais recentes, pois final de 1996, estava sendo regulamentada pela Lei Federal 5 692, de 11 de agosto de 1971, portanto, foi aí que estabeleceram objetivos e metas, tanto para o ensino fundamental quanto para o ensino médio e, porque não, no nosso caso, o ensino superior: onde passou a proporcionar aos educando a formação e desenvolvimento de habilidades e potencialidades como complemento de suas auto-realizações, bem como, preparação para o trabalho e exercício cívico.

As instituições, a qual se trabalhou, a aplicação da avaliação como princípios essenciais para o desempenho do aluno, com prevalência dos aspectos qualitativos sobre os quantitativos, tende no ensino de qualidade a possibilidade de serem fundamentados no sistema educacional, aonde os PCNS podem servir de base e adéqua às necessidades sociais, políticas, econômicas e culturais, realidade que garante aos interesses e ensino/aprendizagens à formação de cidadãos autônomos, críticos e participativos, capazes de atuar com competência, dignidade e responsabilidade junto à sociedade e meio que sobrevivem.

O processo avaliativo dentro do contexto exposto é considerado como elemento fundamental para a melhoria da qualidade de ensino/aprendizagem, deixando de se considerar, como uma ameaça contra o aluno. A avaliação diz respeito não somente a postura do aluno, mas também a do professor.

Bastam os atores do processo educativo serem criativos e inovarem dentro de suas atuações.

A Figura 1, a seguir, mostra o impacto, conservação, preservação e educação ambiental como possibilidade de abertura inovadora pra uma avaliação eficiente. 


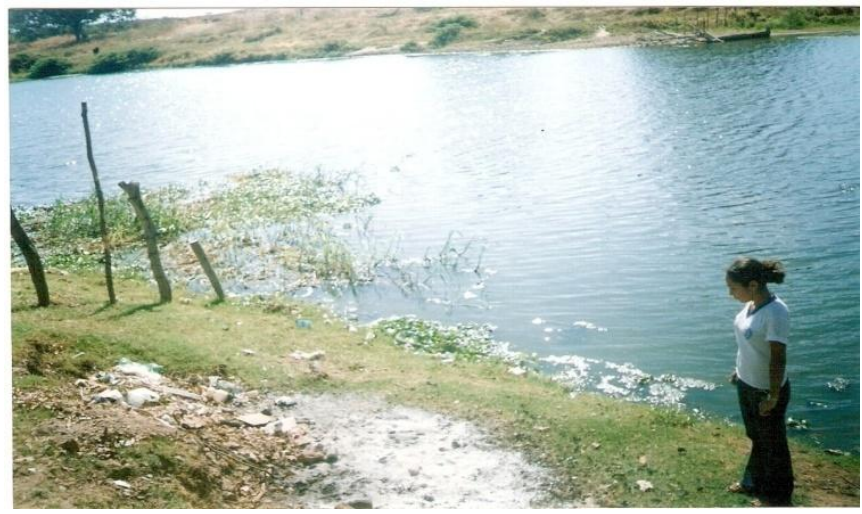

Figura 1 - Aula extraclasse: a degradação ambiental e o Rio Salgado, 2008. Cortesia E.E.F.M. Filgueiras Lima.

As discussões sobre o processo de inclusão social também são importantes instrumentos para mobilização e organização da comunidade. É através da constituição de cada elemento, da troca de experiência e conhecimento técnico que se consegue chegar a um resultado mais elaborado, mais rico em sua criticidade e prazerosa nos dados obtidos. Porém, diante desses princípios, a interação entre sociedade e comunidade acadêmica tende a ser de grande valia.

Evidencia-se, no entanto, que o conceito de avaliação está intrinsecamente monitorado pelas tendências pedagógicas, aonde se busca o tipo de sociedade e homem que se deseja formar. Os profissionais que pretendem discutir e trabalhar os métodos com eficiência devem, pelo menos, buscar possuir sólido conhecimento sobre as tendências, pois serão elas que darão corpo, consistência e seriedade ao trabalho educativo.

\section{A avaliação no ensino superior}

É incontestável o que tem operacionado os evolucionistas para inovar a educação, particularmente no ensino superior. Apesar da guerra dos estudantes contra as provas, as quais são mais utilizadas como instrumento de avaliação, por outro lado, aos professores, não lhes é oferecida uma alternativa razoável e culturalmente contextualizada para substituí-las no processo avaliativo.

Moretto (2007, P. 10) apregoa um passo a ser seguido para transformação da educação: transformam o processo de avaliação numa oportunidade para o aluno ler, refletir, relacionar, operar mentalmente e demonstrar que tem recursos para abordar situações complexas. Em síntese, o aluno deverá demonstrar ter adquirido competência como estudante.

É preciso, segundo o autor, encarar o assunto de forma positiva e construtivista. Ter "esperança e tenacidade" [...] "Não importa onde estejamos em nossa caminhada", o que importa, no entanto, é que "estejamos sempre caminhando". Vamos, então, caminhar juntos neste enfoque: "no ensinar e no aprender em contexto escolar, orientados pelos pressupostos de uma perspectiva que 
privilegie o processo da construção individual do conhecimento, com a mediação do conhecimento socialmente construído".

O processo emancipatório do ensino/aprendizagem nos leva a crê que a possibilidade de dias melhores estão para acontecer, pois o patamar educativo está no bojo das propostas individuais, levando, para tanto, as demandas de cunho sócio/político/econômico. Fazer uma leitura mais atenta dessas questões, refletir e visualizar a praxidade didática, tendo o professor/aluno como eixos dissimuladores das possibilidades, deve ser fatores fundamentais para o progresso acadêmico e se chega a denominadores comuns onde nos aperfeiçoe e nos deixe completamente satisfatório diante da problemática educacional.

\section{A avaliação como norte no ensino/aprendizagem}

Atribuir método avaliativo com profissionalismo não basta só querer, precisa de ética, competência e muita responsabilidade por parte do profissional. Valores tidos como prioridades na da educação. E a avaliação do ensino superior aplicada com ética e dinamismo, ocasionarão norte no campo da profissionalização. Entende-se que o professor deve ser mais valorizado para ser monitorado pelo sistema educacional, aonde deve assumir e cumprir com convicção e competência as tarefas que lhe são atribuídas.

Preparar e ministrar aulas, preparar e corrigir provas, são ações feitas pelos professores no seu cotidiano, visando, no entanto, o sucesso no ensinar. Atos que podem iludir os profissionais menos avisados e atentos. E se não for monitorado e orientado, poderá tomar rumos indesejados. Não devemos pensar, entretanto, em mudanças e inovação na educação de qualidade sem que haja interferência no espaço ensino-aprendizagem, principalmente, na sala de aula.

Não é possível garantir, uma educação de qualidade com professores mal treinados, mal pagos e desestimulados. É a bem da verdade que a formação, uma boa remuneração e o estimulo devem andar de mãos dadas diante do processo evolutivo e servem para que o professor compreenda o seu eficiente papel de agente transformador da sociedade.

A modernidade como pode observar na figura 2 a seguir, direciona a educação para o campo social, onde oportuniza desenvolvimento de competência em vários pontos do saber. Um deles, de relevância incalculável, é o desenvolvimento tecnológico e a criatividade, pois na hora da opção e definição profissional, os conhecimentos e formação acadêmica, adquiridas por eles, poderão ser de serventia absoluta, vez que a capacidade de pensar, observar, relacionar, estruturar, analisar, justificar, sintetizar, correlacionar, inferir, entre outras, preparam o cidadão para o exercício de sua profissão.

Os Parâmetros Curriculares Nacionais (PCNs), de modo geral, apesar de apresentem estrutura curricular completa, aberta e flexível, sugerem a função social das instituições de formação. Podem ser adaptados às realidades locais, não são diretrizes obrigatórias, mas de importância social. 


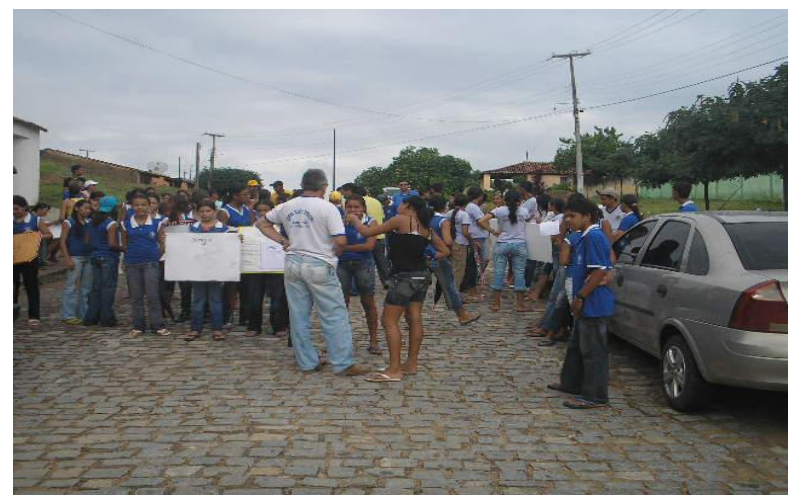

Figura 2 - A educação e os movimentos sociais: professores/alunos, L. da Mangabeira-CE./2008

\section{Avaliar com eficiência rumo ao ensino/aprendizagem}

O problema de avaliar com eficiência rumo à aprendizagem tem sido tema angustiante para a maioria dos professores. Diante disso, Moretto (2007, p. 85) argumenta que,

As dúvidas continuam, os pontos de vista se multiplicam e as experiências se diversificam. O sistema escolar gira em torno desse processo e tanto professores como alunos se organizam em função dele. Por isso a verdade apresentada é: professores e pesquisadores precisamos estudar mais, debater com profundidade e conceituar com segurança o papel da avaliação no processo da aprendizagem.

Avaliar é um processo que gera ansiedade. Indicadores que podemos imaginar o que representa para os alunos. "'Hora do acerto de contas', a 'hora da verdade', a 'hora de dizer ao professor o que ele quer' do aluno. 'A hora da tortura"' (ibid., passim). São algumas das inúmeras indignações e representações enumeradas entre os alunos. Retornamos à argumentação de Moretto para dizer que,

A avaliação da aprendizagem é angustiante para muitos professores por não saberem como transformá-la num processo que não seja uma mera cobrança de conteúdos aprendidos 'de cor', de forma mecânica e sem muito significado para o aluno. Angustia por ter que usar um instrumento tão valioso no processo educativo, como recurso de repressão, como meio de garantir que uma aula seja levada a termo com certo grau de interesse.

Esses álibis são elevados a toda comunidade estudantil com intuito de detectar determinantes, distintas formas de conhecer a educação e ao planejamento pedagógico como difusão 
do raciocínio, proporcionando, então, aos mencionados, atributos que ressonarão em outros sistemas: político, econômico, entre outras. Pois a avaliação é parte do ensino e da aprendizagem. Nunca na visão tradicionalista como está sendo normalmente cogitada e domina o processo de ensino aprendizagem nos dias de hoje.

Diante de "tal diagnóstico, a avaliação precisa ser analisada sob novos parâmetros e tem de assumir outro papel no processo da intervenção pedagógica". Se não a "relação professor-aluno", vista dessa forma, é identificada como uma forma de dominação, de autoritarismo do professor e de submissão do aluno, sendo por isso uma relação perniciosa na formação para a cidadania. A avaliação, na visão construtivista sóciointeracionista, parte do princípio de que o aluno não é um mero acumulador de informação, um receptor-repetidor desse conteúdo. Ele cria e recria e, vez por outra, avalia o seu próprio conhecimento de forma passiva com o professor.

\section{Fatores imprescindíveis e necessários no processo de ensino aprendizagem}

Fator importante para o sucesso na educação superior, seria definir com clareza e precisão os objetivos de ensino, a fim de detectar no decorrer da vida profissional posturas éticas.

Entrar em sala de aula com objetivos perfeitamente definidos é uma das condições estabelecidas para o sucesso no ensinar. "Não só o professor precisa saber dos objetivos, mas seus alunos também", no início, meio e fim da aula. O professor precisa "sempre voltar a explicar seus objetivos, para que os alunos saibam para onde estão sendo conduzidos”. Infelizmente, figura-se evidente, mas isso não se traduz na prática. "Tem-se a impressão de que alguns professores acham que a avaliação é feita para "obrigar" o aluno a estudar. O que não é verdade. Eles devem ser estimulados, motivados para tanto.

\section{As estratégias adequadas para aprender/ensinando}

Estabelecer os objetivos para o ensino e para a avaliação da aprendizagem é escolher estratégias adequadas para a intervenção pedagógica. Daí decorrerá o sucesso da aprendizagem. Ao escolher as estratégias, na visão de alguns profissionais, o professor deverá ter em mente três variáveis fundamentais, relacionadas às características do professor, do aluno e da disciplina. Isto é, em primeiro lugar, saber perguntar. Dominar a arte de perguntar. Uma boa pergunta possivelmente obterá boa resposta.

Em segundo lugar, saber ouvir, pois se souber perguntar, é óbvio que saberá ouvir, uma vez que será tão importante quanto saber perguntar. Finalmente a atuação do emissor e do receptor, na 
zona de atuação. $\mathrm{O}$ que alguns autores a chamam de zona proximal do desenvolvimento do aluno. Moretto (p. 46/7), afirma que o professor,

deve levar em conta seu poder de comunicação, sua linguagem, sua experiência etc. Assim, um professor que tem boa comunicação oral, que sabe fazer seu corpo 'falar', que domina facilmente um grupo de alunos pela palavra, que administra bem a entonação de voz, pode usar com mais frequiência a estratégia da aula expositivo/participativa do que um professor que é naturalmente tímido ou mesmo gago. O docente com essas características pode tanto quanto o primeiro ser um excelente professor. Para isso deverá escolher outras estratégias de ensino, adequadas às suas características de timidez ou gagueira. Por essa razão, ele precisa conhecer-se, saber de suas potencialidades e limites. Por exemplo, precisa saber se ele é mais visual ou mais auditivo ou sinestésico. Com isso pode explorar suas potencialidades utilizando estratégias de ensino relacionadas com suas próprias características, mas cuidando de adequá-las às de seus interlocutores.

Entendem-se o citado profissional que as estratégias de ensino precisam estar ligadas às características do docente, elas, portanto, precisam também respeitar as dos alunos, vez que da forma que serão consideradas as estratégias do professor ligadas às suas características, também devem respeitar as do aluno. O que, às vezes, não serão levadas em consideração por profissionais. É preciso, entretanto, o professor buscar o sucesso de sua atividade na relação de mediador. Como, realmente, age o mediador?

Foi pensando nesse princípio que buscamos detectar na pesquisa de campo que em cada "nível de ensino" e em cada "contexto social e psicológico" é necessário usar estratégias adequadas ao público. Vez que é preciso, sim, que o professor tenha em mente uma visão epistemológica bem definida. Se estiver ou não de acordo com as perspectiva de relacionamento humano, levando, para tanto, o meio ao qual sobrevive o público, isto é, o aluno. O conhecimento do contexto social destes (Figura 3) é de fundamental importância para o professor detectar o que é melhor para o ensino/aprendizagem.

$\mathrm{Na}$ lida professor/aluno não é imperioso o professor conhecer, um por um, os alunos. Era muito bom se assim o fosse. Mas que saiba pelo menos das principais características do grupo, bem como, do conhecimento psicológico e cognitivo. A partir delas, o professor deve trabalhar os valores, conceitos, linguagens e atitudes, ou seja, uma infinidade de conceitos. 


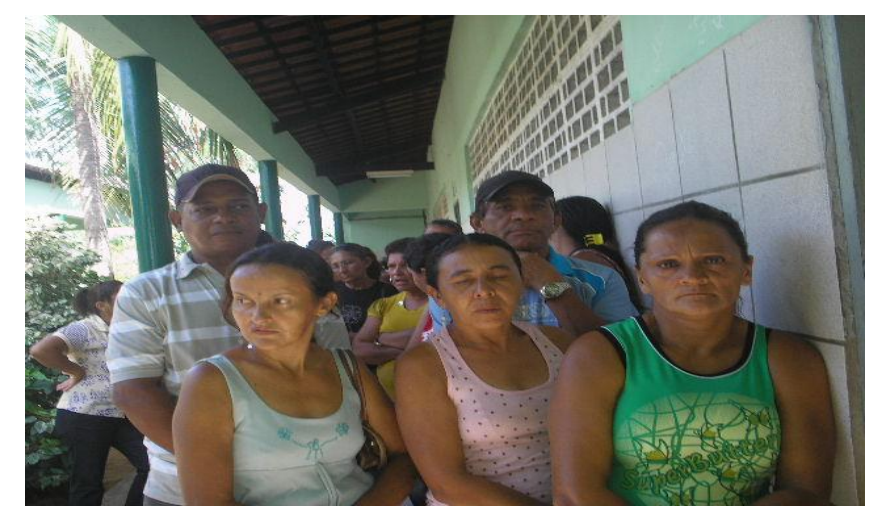

Figura 3 - Contexto sócio/comunidade escolar: cortesia E.E.F.M. Alda Ferrer A. Dutra, L. da Mangabeira-CE./2009.

De posse dessas informações o professor formula as estratégias e plano de trabalho. Pela forma aplicada parece estético na teoria, só que na realidade as coisas começam a se alongar e transferir responsabilidades, como faz os esportistas quando jogam bola de gude: aonde, quando e a quem atribuir à responsabilidade do mau posicionamento. Os professores, no entanto, poderiam se utilizar de estratégias distintas para diferentes níveis e faixas etárias. O que poderão alguns até fazer, mas se distanciam, na maioria das vezes, quando se pensa no padrão nacional. O que deveria buscar um denominador comum entre todos, mas aquém atribuir tamanha responsabilidade!

\section{A avaliação e a formação no contexto pedagógico: mais do que treinar o educando}

Na busca do ensino superior que desejamos induz-se o observador, em primeiro lugar, à questão da formação docentes/discentes ao lado da reflexão sobre a prática educativo-progressiva à autonomia dos seres humanos. A esta se incorpora a análise de saberes fundamentais àquela prática: formar é muito mais do que puramente treinar o educando no desempenho de destreza. Fato de interesse ao que diz respeito a homens/mulheres, assunto, aos quais, saio e retorno com o mesmo sabor de quem a ele estou nele pela primeira vez.

Paulo Freire (2007, p.14, passim) direciona aos leitores através da "pedagogia da autonomia": o "tom de raiva, legítima raiva, que envolve o meu discurso quando me refiro às injustiças a que são submetidos os esfarrapados do mundo". Daí passa-se ao segundo ponto para dizer que é, realmente, a estas injustiças aos esfarrapados que se desdobra a comentar sem assumir nenhuma ordem própria, mas um ar de observador imparcial, objetivo, seguro dos fatos e dos acontecimentos, em tempo hábil e convicto do que detectamos.

Quem observa o faz de certo ponto de vista, o que pode até elevar o observador, ou induzir esse observador ao erro. Dessa forma coloca-se na posição de quem se firma a obedecer a um ser superior, que as boas mentes dizem que: aquele que faz cumprir as ordens superiores não peca por 
erros incomuns, pois não fez mais do que sua obrigação, uma vez que para aquilo fora determinado. Não devemos situar o observador em erro se assim o cometer, pois a ele (ser superior) nos submetemos.

\section{O erro não é ter um ponto de vista, mas absolutizá-lo}

O erro, na verdade, não é ter certo ponto de vista, mas absolutizá-lo e desconhecer que, mesmo do acerto de seu ponto de vista é possível que a razão ética nem sempre esteja com ele. Portanto, Srs. professores/a, educadores/a, gostaríamos de sublinhar a nós mesmos, a responsabilidade ética no exercício de nossa tarefa e, ao mesmo tempo, sublinhar essa responsabilidade àqueles (a) que se acha em formação para exercê-la. Sabe por quê? Porque estamos falando não da ética que se reporta Paulo Freire: a "ética menor, restrita, do mercado, que se curva obediente aos interesses do lucro", mas da "ética universal do ser humano".

Entretanto, a ética que gostaria de expressar é a que condena a exploração da força de trabalho, que condena por ouvir dizer, "falsear a verdade, iludir o incauto, golpear o fraco e indefeso, soterrar o sonho e a utopia, prometer sabendo que não cumprirá a promessa", como bem fazem a maioria dos políticos dos tempos modernos, "testemunhar mentirosamente, falar mal dos outros pelo gosto de falar mal”, entretanto. Muito pelo contrário, a ética a que estamos nos reportando é a ética dentro do contexto pedagógico, aonde a avaliação do ensino superior decorre por caminhos, às vezes, indevidos e a responsabilidade passam a ser atribuída a quem não é de direito, vez por outra, a comunidade acadêmica.

A ética a que falamos, envolve-se a família, grupo gestor, reitores, coordenadores de curso, professores (a), alunos, funcionários das repartições educativas é aquela que se sente traída e atraída, como negada nos comportamentos, como se coloca Freire (1996, p.16):

A ética de que falo é a que se sabe afrontada na manifestação discriminatória de raça, de gênero, de classe. É por esta ética inseparável da prática educativa, não importa se trabalhamos com crianças, jovens ou com adultos, que devemos lutar. E a melhor maneira de por ela lutar é vivê-la em nossa prática, é testemunhá-la, vivaz, aos educadores em nossas relações com eles. Na maneira como lidamos com os conteúdos que ensinamos, no modo como citamos autores de cuja obra discordamos ou com cuja obra concordamos. Não podemos basear nossa crítica a um autor na leitura feita por cima de uma ou outra de suas obras. Pior ainda, tendo lido apenas a crítica de quem só leu a contracapa de um de seus livros.

Por outro lado, Paulo Freire dispõe a dizer que a presença do ser humano no mundo como algo original e singular é para mostrar a todos nós que essa presença não é apenas pessoal, física, e sim, mais do que um ser no mundo. Isto é, ele quis enfatizar que o homem se tornou uma presença no 
mundo, com o mundo e com os outros e, ao mesmo tempo, se colocando nesse mundo como se fosse o outro. Nesta linha de raciocínio, o autor esclarece:

não aceitar a concepção pedagógica deste ou daquela autora e devo inclusive expor aos alunos as razões por que me oponho a ela mas, o que não posso, na minha crítica, é mentir. É dizer inverdades em torno deles. O preparo científico do professor ou da professora deve coincidir com sua retidão ética. É uma lástima qualquer descompasso entre aquela e esta. Formação científica, correção ética, respeito aos outros, coerência, capacidade de viver e de aprender com o diferente, não permitir que o nosso mal-estar pessoal ou a nossa antipatia com relação ao outro nos façam acusá-lo do que não fez são obrigações a cujo cumprimento devemos humilde, mas perseverantemente nos dedicar (FREIRE ,1996. p.17)

Por isso é que damos ênfase ao processo de ensino aprendizagem dentro das academias, tendo em vista a avaliação como ponto de partida e não de chegada.

\section{A importância da avaliação no processo de ensino aprendizagem}

Aos fatores mencionados, acrescenta-se esse que de forma diversas tem sido acompanhado há mais de quinze (15) anos, quando nas expectativas acadêmicas fez-se parte: a avaliação do ensino superior e a contribuição dos ministrados em relação aos ministradores, inclusive utilizando-se de enfoques teóricos, pois a argumentamos ser plausíveis e está ancorado em nível de sociedade local, em concomitância com o global. Ainda que os planos local/regional e nacional/internacional se apresentem interligados. Por esses e outros vieses é que nos entregamos ao objeto de estudo, interativamente e insistentemente, bem como, eternos seres condicionados, mas não determinados a fazer o que os outros gostariam que fizéssemos para obter os objetivos deste trabalho.

A problemática deste estudo foi idealizada a partir da participação nas aulas das Licenciaturas Plenas em História (1999) e Ciências Biológicas (2009), bem como, das Especializações "Lato Sensu" em História do Brasil (2001) e Educação Ambiental.

Realmente é dentro dessa vertente do saber que se impulsiona a construção de conhecimento e, sem querer direcionar responsabilidade a quem quer que seja, por mais polêmica que a avaliação se posicione, as reflexões vão continuar, assim como os debates e a crescente presença nas propostas e práticas de gestão administrativa.

Tendo a avaliação como eixo e como trabalhar em sala de aula, são e serão de fundamental importância, qual sejam suas dimensões e níveis de ensino. Por outro lado, sabe-se que as questões administrativas estatais intervêm de forma, até certo ponto, inconsciente, nas administrações educacionais públicas e privadas. Outra realidade que precisa ser levado em consideração, vez que a escolha e seleção dos profissionais para atuarem nessa área sempre passam, na maioria das vezes, pelo 
crivo de suas determinações. Embora sendo escolhido democraticamente através de seus votos preferenciais.

Não adianta camuflar o problema, que é bastante corriqueiro e prejudicial à evolução educacional, pois as maiores partes dos debates ocorridos dentro das universidades e instituições afins estão submetidos e centrados dentro desses patamares e os níveis de ensino/aprendizagem, à avaliação em geral, pode ser a questão metodológica e operacional. O maior problema é como, efetivamente, resolver os entraves pedagógicos e político e aprimorar a dimensão educativa levando em conta a realidade tão corriqueira nas escolas e universidades do país.

\section{Avaliação e informação na regulação da docência superior}

O caminho para a conjugação das medidas: avaliar e informar na regulação da docência superior circundam em torno de três eixos: democratização da gestão, valorização do magistério e qualidade de ensino. Pergunta-se, até que ponto as administrações educativas está se tornando mais eficiente e democrática. Existe-se uma mudança de paradigma para os recursos que está sendo canalizado para a montagem do complexo de regulação, onde regule medida-avaliação-informação, com base no pressuposto de seu potencial para induzir, a princípio, a reforma da gestão da educação básica, como desafios a se alcançar eqüidade, qualidade e eficiência no ensino superior.

Vejamos, por outro lado, o que tem a dizer Dirce Nei (2007, P. 118/125, respectivamente), diante da reflexão pedagógica:

Um aspecto de cunho político, pedagógico e técnico que ocupou agentes estatais da esfera educacional, desde o ingresso nos anos 2000, se refere a como construir uma mediação entre instâncias avaliadoras e os sujeitos que detêm o poder de imprimir significado e sentido prático aos 'achados' possibilitados pelo complexo de 'medida-avaliação-informação'. O problema de como tornar efetiva essa via de regulação da educação básica tem sido a grande questão posta ao Estado central. Quando se atenta para isso, é preciso lembrar que as manifestações de agentes estatais geralmente apontaram 'a escola' como a principal responsável pela viabilização da qualificação do ensino. O pressuposto é o de que grande parte dos problemas existentes se deve ao que ocorre ou não na escola e que cabe a ela resolvêlos com a contribuição dos pais e da sociedade.

A despeito da crescente amplitude e sofisticação da regulação da avaliação como meio de aperfeiçoamento social, têm-se no cenário da educação, denúncias correntes na imprensa, reclamos populares amplificados pelo jogo de disputas eleitorais e pesquisas acadêmicas permitem ver que apenas se logrou metamorfosear o problema, mantendo-se ativa uma pedagogia da exclusão. Pode-se até certo ponto ser irreal, mas não podemos negar a concretização de políticas de inclusão escolar e social no país ser por demais frágeis. 


\section{O quê, Quem e Para quê avaliar?}

Quanto ao estímulo e sentimentos das pessoas na adoção favoráveis de opções feitas centralmente no tocante o que avaliar, quem avaliar e para que avaliar, no entanto, reportamos à inquietação inicial: avaliar o ensino superior que desejamos. Questão profundamente interessante. Pois se deve usar o processo e recursos avaliativos de forma correta na prática, ação do ensino/aprendizagem, onde vai determinar e direcionar valores, estimulando-se desempenho e rendimento. Fundam-se, com isso, razões meramente econômicas, políticas, culturais e pedagógicas próprias à regulação emergente na educação.

Nesse processo de suma importância deve levar em consideração o princípio de responsabilidade individual e social, tanto do docente como do discente, pois "não é de somenos importância se interrogar quanto aos caminhos que a sociedade brasileira está a trilhar com processos educativos calcados nos pressupostos salientados neste trabalho". Então, o que avaliar? A quem avaliar? E para que avaliar? No entanto, a gestão democrática da educação busca esse caminho por demais difícil, mas, como se diz na gíria, nada é impossível. Ou, para os mais otimistas, o impossível não existe para aqueles que desejam encontrar soluções pertinentes.

Está na natureza do homem o que é público dar conhecimento ao que interessa a todos. Concorda-se com Dirce Nei, (P. 179, passim) quando diz que "ver e ser visto, conhecer e dar a conhecer, são dimensões do ser público que se opõe aos segredos das coisas secretas, enquanto dimensões próprias do privado e concernente ao indivíduo na sua pessoalidade e na propriedade de si”. Entretanto, o compromisso com a verdade eleva o indivíduo avaliar para transformar em vista o interesse público. Agora, avaliar o quê, realmente.

Em primeiro lugar, avaliar a atuação do indivíduo, a sua equidade, o seu desempenho na aquisição de conhecimentos teórico-práticos, o desenvolvimento de habilidades, ensejando transformar a pessoa para que essa "prática priorize a democratização das relações sociais e a realização de direitos imprescindíveis à qualidade de vida de todos”. Não podemos esquecer, portanto, que esse indivíduo, ao qual nos reportamos se trata do conjunto que forma a comunidade estudantil, ou seja, família/escola, grupo gestor/sistema instituições, pais e filhos, entre outros, pois se tende englobar a toda sociedade envolvida no processo educativo.

\section{Considerações finais}

Cada um de nós, quer sejamos pesquisador ou educador, cientista ou leigo, mestre ou aluno, participante de uma sociedade altamente competitiva, sabe que, no mundo moderno, o estudo das ciências, notadamente da pedagogia, se torna a cada dia mais importante e atraente na formação global 
dos cidadãos. E a pedagogia está, a todo instante, nos envolvendo e auxiliando na explicação dos fenômenos sociais.

A verdadeira responsabilidade é estrutural, pois a questão política e pedagógica paira sobre todas essas realidades educativas. Isto é óbvio, temos que, no mínimo, admitir. O presente constatou que docentes e discentes no ensino superior, ainda necessitam de ações supervisionadas e monitoradas, visto que, se assim não o for, os agentes envolvidos no processo educativo não cumprem com dignidade e eticidade as normas norteadoras.

Além disso, é necessário o educando, bem como, o educador, buscarem priorizar a criatividade, a compreensão dos limites e estímulos à autonomia do sujeito, em relação às suas próprias capacidades. Por que, embora de forma inconsciente, o que se vê nas academias são concepções rudimentares de ensino e aprendizagem, no tocante a compreensão dos papeis de professor e aluno, e de metodologias ainda incipientes.

A avaliação nas instituições de ensino superior, carecem de inovação, considerando as expectativas e as necessidades contextuais atuais, em termos tecnológicos. Também, por outro lado, preciosa valorizar o trabalho do educador, fornecendo-lhe salário digno, formação equiparada com a realidade e orientação adequada, se se pretende um bom desempenho dos alunos.

Uma maior discussão sobre a melhor forma de avaliar o aluno, e este, o professor, deve se fazer presente nas academias. Muitos professores ainda se utilizam de métodos arcaicos e impróprios na hora de verificar e avaliar os objetivos de aprendizagem. Esta prática, nem sempre eficiente, expõe o aluno, levando a reprovações incoerentes e estatísticas absurdas.

\section{Referências}

AGUIAR, Ubiratan. Lei de diretrizes e bases da educação nacional - LDB/ Comentada. $2^{\text {a }}$ Edição Revisada. Editora Afiliada - Premius Editora. Fortaleza-CE. 2003.

CAMPOS, Victor Emídio. Processo Avaliativo: um estudo de caso. Monografia de conclusão do Curso de Graduação em Ciências Biológicas da Universidade Regional do Cariri - URCA, CratoCE., 2009.

FREIRE, PAULO. Pedagogia da autonomia: Saberes Necessários à Prática Educativa. Editora: Paz e Terra, São Paulo, 1996.

FREITAS, Dirce Nei Teixeira de. Avaliação da educação básica no Brasil: dimensão normativa, pedagogia e educação. Autores Associados, Campinas S. Paulo, 2007.

GADOTTI, Moacir. ROMÃO, José E. (Org.). Autonomia da escola: princípios e propostas. Cortez, São Paulo, 1997.

LIBÂNEO, José Carlos. Democratização da escola pública: a pedagogia crítica-social dos conteúdos. 11 ed. Loyola, São Paulo, 1993. 
. Didática. In: Avaliação escolar. Cortez, São Paulo, 1994.

MORETTO, Vasco Pedro. Prova: um momento privilegiado de estudo, não um acerto de contas. $7^{\mathrm{a}}$

Ed. Lamparina editora, Rio de Janeiro, 2007.

SILVA, Delcio Barros. As principais tendências pedagógicas na prática escolar brasileira e seus pressupostos de aprendizagem. Disponível em http://www.ufsm.br/lec/01_00/DelcioL\&C3.htm. Acesso em 14.06.2010.

\section{Sobre o autor:}

(1) Victor Emídio Campos é Licenciado em História e Ciências Biológicas, com Especialização em História do Brasil. É especializando em Educação Ambiental pela Universidade Regional do Cariri URCA. Mestrando em Ciências da Educação pela Universidad San Carlos - Paraguai.

E-mail: victoraltha@ hotmail.com

Como citar este artigo (Formato ISO):

CAMPOS, V.E.. O Ensino Superior que desejamos. Id on Line Revista de Psicologia, Julho de 2010, vol.1, no.11, p.25-38. ISSN 1981-1189. 